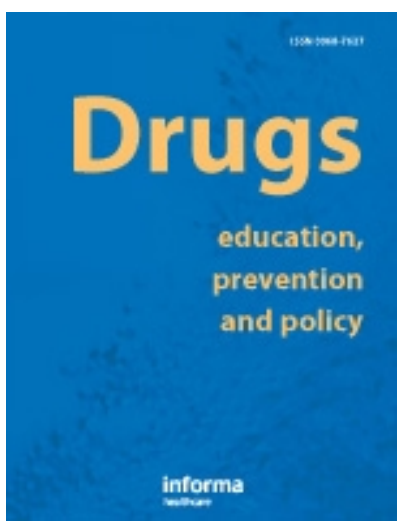

\title{
Adolescents' reactions to, and perceptions of, dissuasive cigarettes: A focus group study in Scotland
}

\begin{tabular}{|r|l|}
\hline Journal: & Drugs: Education, Prevention \& Policy \\
\hline Manuscript ID & CDEP-2019-0139.R1 \\
\hline Manuscript Type: & Original papers \\
\hline Keywords: & Dissuasive Cigarettes, Tobacco Control, Focus Groups, Adolescents \\
\hline \multicolumn{2}{|l}{} \\
\end{tabular}

\section{SCHOLARONE \\ Manuscripts}




\begin{abstract}
The cigarette stick, as the primary form of packaging and the object of consumption, is an increasingly important marketing tool for tobacco companies. It could, however, also be used to communicate health messaging. We therefore explore adolescents' perceptions of cigarettes designed to dissuade smoking. Eight focus groups were conducted with 16-17 year-olds in Scotland ( $n=36)$ between November 2017 and November 2018. Groups were segmented by gender and smoking status. Participants were shown four dissuasive cigarettes; one displaying the warning 'Smoking kills'; one featuring the word 'TOXIC' and a skull and crossbones image; and two unattractively colored cigarettes (darker and lighter green). For comparison, participants were also shown a standard cigarette (white cigarette paper and imitation cork filter). All four dissuasive cigarettes were considered less attractive and more harmful than the standard cigarette, particularly among never-smokers. Some participants considered the green cigarettes to be ugly, and the on-cigarette warnings to be embarrassing and off-putting. Although reactions were mostly negative for all four dissuasive cigarettes, participants considered the on-cigarette warnings more off-putting than the green cigarettes. Participants did not generally believe that the dissuasive cigarettes would encourage cessation among established smokers, but that they may deter uptake among young people.
\end{abstract}




\section{INTRODUCTION}

2 As countries worldwide are increasingly adopting standardized tobacco packaging (six

3 countries to date), or introducing large pictorial health warnings on packaging (over 100

4 countries to date), the cigarette stick has assumed greater importance as a marketing tool

5 (Moodie, Hoek, Scheffels, Gallopel-Morvan \& Lindorff, 2018; Moodie et al., 2019b). This is

6 perhaps best demonstrated by the significant global growth of 'capsule' cigarettes, which

7 contain one or more capsules in the filter that can be burst to change the flavor (Moodie,

8 Thrasher, Cho, Barnoya \& Chaloupka, 2019). Other cigarette designs, such as longer and

9 slimmer cigarettes, are often perceived as stylish, particularly among female smokers

10 (Anderson, Glantz \& Ling, 2005; Carpenter Wayne \& Connolly, 2005; Doxey \& Hammond,

11 2011). Tobacco companies have a long history of exploiting any gaps in tobacco control

12 legislation (WHO, 2009), and recent studies suggest that they are also doing so in markets with

13 standardized packaging, particularly via filter innovation (Moodie et al., 2018). For example,

14 aside from the introduction of new capsule brand variants in the United Kingdom (UK), one

15 tobacco company has introduced cigarettes with star shaped filter tips, named Sterling Dual

16 Star Edition (Figure 1).

$17 \quad$ [Figure 1]

18 The UK's standardized packaging legislation requires cigarettes to have a white or 19 imitation cork filter and white paper casing (Department of Health, 2016; Moodie et al., 2019a).

20 The legislation also permits the display of a brand variant name in a standardized font just 21 below the filter, unlike in Australia and New Zealand where only an alphanumeric code can be 22 displayed (WHO, 2018). Although a ban on flavors in cigarettes, including flavor-changing 23 capsules, will take effect in May 2020, there have been no other attempts to control the design 24 of cigarettes in the UK (UK Government, 2016). There is a growing body of evidence, 
25 however, which suggests that 'dissuasive cigarettes' provide a further opportunity to promote

cessation and reduce uptake, and can transfer some of the health messaging from the secondary packaging (e.g. pictorial and written health warnings on the outer packaging) onto the actual object of consumption. Suggested dissuasive designs include unattractively colored cigarettes (e.g. green and yellow) and on-cigarette warnings (e.g. average minutes of life lost from smoking each cigarette, smoking kills, short and long-term harms, and financial and social costs) (Drovandi, Teague, Glass, \& Malau-Aduli, 2019a, 2019b; Gendall, Eckert, \& Louviere, 2016; Hassan \& Shiu, 2013; Moodie, Hiscock, Thrasher \& Reid, 2018).

Dissuasive cigarettes are considered a low cost opportunity to reach consumers at the point of consumption (Moodie, 2018). They are supported by research with consumers, marketing experts, and healthcare practitioners, with findings suggesting that they reduce the appeal of smoking and intentions to try cigarettes, and increase perceptions of harm and cessation (Drovandi, et al., 2019a, 2019b, 2019c; Hassan \& Shiu, 2013; Hoek, Scheffels, Gallopel-Morvan \& Lindorff, 2019; Gendall, Eckert \& Louviere, 2016; Lund \& Scheffels, 2018; Moodie, 2016; Moodie, MacKintosh, Gallopel-Morvan, Hastings, \& Ford, 2016; Moodie et al., 2017b; Moodie, Hiscock, Thrasher \& Reid, 2018; Moodie, Hoek; Moodie et al., 2019b; Moodie, Purves, McKell \& Andrade, 2015). Recent research has also suggested that the ability of dissuasive cigarettes to deter young people from smoking may be enhanced through the inclusion of images (e.g. skull and crossbones warning symbol), rather than just a colour or text warning (Gallopel-Morvan, Droulers, \& Pantin-Sohier, 2019).

There are at least five reasons why adolescents are an important target audience for dissuasive cigarettes. First, adolescents have been an important target market for tobacco companies for decades (Ford, Moodie, MacKintosh, \& Hastings, 2013; Hastings \& MacFadyen, 2000; Kotnowski \& Hammond 2013; MacFadyen, Hastings \& MacKintosh, 2001), and this continues to be the case through innovations such as capsule cigarettes (Moodie 
et al., 2019). Second, adolescents often obtain single cigarettes, commonly from friends or family members, or by purchasing single cigarettes from retail outlets, including in countries where this is not permitted (Donaghy et al., 2013; Tjelta, Ritchie \& Amos, 2016; Wackowski et al., 2017). In doing so, adolescents may therefore avoid the on-pack pictorial health warnings or dissuasive influence of standardized packaging. Third, with prices continuing to increase in many markets, single cigarettes are an increasingly affordable option for price-sensitive young people. In the UK, for instance, tobacco was 30\% less affordable in 2017 than in 2007 (NHS

Digital, 2018), and prices have continued to rise after standardized packaging was implemented (Critchlow et al., 2019). Fourth, as of May 2017, a minimum pack size of 20 factory-made cigarettes and 30 grams of rolling tobacco became mandatory across the EU, which has removed the option of the smaller and more affordable pack sizes favored by young people (e.g. 10 cigarettes or 12.5 grams of rolling tobacco) (Centre for Tobacco Control Research, 2012). Finally, research has found that the cigarette itself may be considered cool or stylish among adolescents, particularly slim cigarettes, those with decorative designs, and capsule cigarettes (Ford, Moodie, MacKintosh \& Hastings, 2014; Moodie, Ford, MacKintosh \& Purves, 2014). It is therefore possible that this communicative power could be used to promote health behaviors, while simultaneously removing an opportunity to promote tobacco brands and smoking.

While previous research consistently suggests that dissuasive cigarettes reduce the appeal of smoking, there remain gaps in the evidence. There is limited qualitative research with adolescents, despite their importance as a target audience. In addition, few studies have examined the influence of dissuasive cigarettes in a market where standardized packaging is mandatory (Drovandi et al., 2019a, 2019b, 2019c), or the effect of including warning images on the cigarette. In this study, we therefore explore perceptions of, and responses to, four 
75 that the Scottish Government plans to review the evidence on dissuasive cigarettes as part of their current tobacco control plan (Scottish Government, 2018).

\section{METHODS}

\section{Design and sample}

80 Semi-structured focus groups were conducted with 16-17 year olds in secondary schools in

81 Scotland (Stirling, West Lothian and North Ayrshire), between November 2017 (six months after standardized packaging became mandatory) and November 2018 (18 months after standardized packaging became mandatory). This timeframe was determined by the speed of response by local authorities and schools, and availability to conduct the groups (e.g. accounting for school holidays). The focus groups covered both reactions to standardized packaging (reference removed for anonymization) and alternative methods of discouraging smoking uptake (e.g. dissuasive cigarettes and audio warnings on packs). Only the data related to dissuasive cigarettes are reported here. In return for taking part, all participants were given the opportunity to enter a ballot to win a personal computer tablet.

As with previous research on tobacco packaging, groups were segmented by gender 91 (Ford et al., 2013a; Ford et al., 2013b) and smoking status (never smoker, ever smoker)

92 (Drovandi et al., 2019a) using a pre-group questionnaire. Participants were asked how often they smoked, with five response options ranging from 'I have never smoked, not even a puff or two' to 'I smoke every day' (Bauld et al., 2017). Those who selected 'I have never smoked not even a puff or two' were categorized as never-smokers, and those who selected any other option were categorized as 'ever-smokers'.

97 Eight focus groups were conducted, comprising three ever-smoker groups (two female, one male) and five never-smoker groups (three male, two female). Due to a fault with the 
99 recording equipment, the section on dissuasive cigarettes was not captured from one of the

100 never-smoker female groups. Therefore, only seven groups were used in the analysis, providing 101 a final sample of 36 participants (Table 1).

102

103 [Table 1]

104

105

\section{Materials}

106 Participants were exposed to, and given the chance to handle, five cigarettes. Four of the

107 cigarettes had designs intended to be dissuasive: (1) a cigarette with the text warning 'smoking 108 kills'; (2) a cigarette with the text message 'TOXIC' and a skull and cross bones image; (3) a 109 dark green cigarette; and (4) a lighter green cigarette' (Figure 2). The warning 'smoking kills'

110 was chosen as this message is commonly communicated by public health bodies (e.g. World 111 Health Organization, 2019), it is frequently recalled by adolescents from the outer packaging 112 (Moodie, MacKintosh \& Hastings, 2013), and it is a design used in previous dissuasive 113 cigarette research (Moodie et al., 2015; Moodie et al., 2019). The green cigarettes were chosen 114 based on previous research, where they have been deemed to be unappealing (Hoek et al., 2016; 115 Lund \& Scheffels, 2018; Moodie et al., 2018b). We featured two green designs to examine 116 whether colour tone influenced reactions. The 'TOXIC' design, a combination unique to this 117 study, was intended to show cigarettes as being dangerous and harmful, and therefore featured 118 language and iconography that is often mandated on (or associated with) other hazardous and 119 harmful substances (e.g. on chemicals such as bleach) (Health and Safety Executive, 2019).

120 While pairing both an image of a skull and crossbones and the wording 'TOXIC' is unique to 121 this study, the image used is similar to a design previously investigated (Gallopel-Morvan et 122 al., 2019). We also included a 'standard' cigarette with an imitation cork filter to provide a 123 comparator to the dissuasive cigarettes. 
124 The research team made the five cigarettes using specially designed printed stickers, 125 which were applied to the cigarettes. The cigarette paper on each sticker had the wording 126 'Brand, King Size' below the filter in a standardised font, where the brand name would usually 127 appear, similar to how brand variant name would appear on cigarette sticks in the UK post128 standardised packaging. This approach is consistent with previous research on dissuasive 129 cigarettes (Moodie et al., 2017) and ensured that the presence of a recognizable brand name 130 did not influence perceptions or reactions.

132 [Figure 2]

\section{PROCEDURE}

135 Ethical approval was obtained from [Institution name removed for blind review]. Permission 136 to conduct the research was sought from local authorities and, once obtained, schools in those 137 jurisdictions were contacted by letter and followed up one or two weeks later with an email 138 and phone call. In schools that agreed to participate, potential participants were informed about 139 the study aims by the researcher or a designated teacher within the school, and provided with 140 an information sheet, privacy notice, consent forms, and also pre-group questionnaires (to 141 perform group segmentation).

142 All groups were conducted in assigned rooms at the school, and were facilitated by DM.

143 To avoid potential response bias or non-disclosure among participants, teachers were not 144 present during the groups. At the start of each group, participants were reminded that their 145 involvement was voluntary, they were free to withdraw at any time, their answers would be 146 confidential, and all data provided would be anonymized. Groups lasted between 30-45 147 minutes, with length dictated by scheduled class period in each school. Within each group, 148 approximately 15 minutes were allocated to discuss the dissuasive cigarettes, and this took 
149 place after discussing reactions to standardized packaging (reference removed for 150 anonymization).

151 Before being shown any of the cigarette stimuli, the section began by asking 152 participants what they thought cigarettes look like, where they recall seeing them, and who 153 they recalling seeing with cigarettes. In the first group conducted, all five cigarettes were then 154 shown simultaneously. This, however, resulted in participants only focusing on certain 155 cigarettes, rather than gaining their perspective on all five individually. Therefore, in all other 156 groups, participants were shown the standard cigarette and 'smoking kills' cigarette first. They 157 were given time to look at them, pass them around, and discuss reactions. The 'TOXIC' 158 cigarette was then passed around on its own and, finally, both green cigarettes were distributed together. The dissuasive cigarettes were given out in this order so that participants were first commenting on two designs that explicitly carried on-cigarette warnings (i.e. smoking kills and 'TOXIC'), followed by two designs with dissuasive colours, thus allowing participants to 162 discuss their reactions to different dissuasive approaches. All five cigarettes were brought out 163 of a standardized cigarette pack to simulate a real cigarette being taken from packs available in 164 the UK market.

165 Once all cigarettes had been distributed, participants were asked whether they liked or disliked any of the cigarettes, how each cigarette made them feel about smoking, and to imagine 167 what kind of person each cigarette may be - a personification technique used in previous 168 cigarette packaging research (Ford et al., 2013a). Participants were also asked if they thought 169 people their age would find the cigarette designs appealing or unappealing, and if they thought 170 the dissuasive cigarette designs were off-putting. To help facilitate discussions, participants 171 were also asked to rank each cigarette based on appeal, harm and taste (Ford et al., 2013a). 172 Show cards were placed on the table (most appealing/least appealing, strongest tasting/weakest 
173 tasting and most harmful/least harmful) and participants were asked to place the cigarettes 174 based on what they thought; they were encouraged to work together and discuss their decisions.

176 ANALYSIS

177 All groups were audio recorded and transcribed verbatim by DM. Transcripts were analyzed using NVivo 11. Consistent with previous qualitative tobacco control research with adolescents in the UK (Ford et al., 2013a; Moodie et al., 2019), we identified shared meaning and common attitudes across the groups using the six sequential stages of thematic analysis recommended by Braun and Clarke (2012). Initially, DM read over the transcripts several times to enable

182 familiarization with the groups and discussion, and checked the transcripts against the audio recordings to ensure accuracy. A thematic coding framework was created in Nvivo based on initial common themes identified in the transcripts. All emerging themes were subsequently refined based on the framework created. DM generated the initial thematic codes (e.g. dissuasive cigarettes being off-putting and embarrassing) and these were refined based on

187 discussions with $\mathrm{NC}$ and $\mathrm{CM}$, and then organised under key headings based on the key areas explored in the topic guide: (1) general perceptions of, and exposure to, cigarettes; (2) initial reactions to, and perceptions of, the dissuasive cigarettes; (3) harm perceptions of dissuasive cigarettes; and (4) perceived impact on smoking attitudes and behaviour of dissuasive cigarettes. Matrix coding was also used in NVivo to categorize themes by smoking status and

192 gender to explore any between group differences. Concerning the cigarette sorting activity, 193 images were taken of the cigarettes only once they had been organized. This section was analyzed separately by denoting the order from each group alongside the conversation from the and gender). 


\section{$198 \quad$ RESULTS}

\section{General perceptions of, and exposure to, cigarettes}

200 Across all groups, participants recalled seeing cigarettes frequently, with several participants 201 suggesting that they see them every day. Places where participants recalled seeing cigarettes 202 included public spaces, at home (if family members smoked), or at school (e.g. pupils or parents 203 picking up their children). Some participants mentioned that they recalled seeing the cigarette 204 more often than the outer packaging.

I probably see them every day, if you're walking home, you'll always see someone walking with a cigarette in their hand or something (Male ever-smoker)

It depends on who you're with, really, if your family smoke you'll see them a lot, if your friends smoke you'll see them a lot (Female ever-smoker) At home, in the street, at school, at work (Female ever-smoker)

Everywhere, if I'm walking home I see someone walking their dog and they've got one [a cigarette], picking their children up from school (Female never-smoker)

217 When asked to describe what cigarettes are like, most participants described the 'standard' 218 cigarette design (i.e. imitation cork filter and white paper). Some female ever-smokers, 219 however, were knowledgeable of different cigarette types (e.g. capsule cigarettes) and 
220 indicated that they thought these alternative features or designs might encourage consumption.

221 Several participants, both male and female, also referred to cigarettes made with hand-rolling 222 tobacco (roll-your-own cigarettes).

You get white ones, you get ones with the wee Crushball [a flavor-changing capsule] (Female ever-smoker)

They're like improving them cause like you get the like the wee things that you squish that makes it like menthol or something... like that's encouraging people to try it cause they want to know what that's like (Female never-smoker)

\section{Initial reactions to, and perceptions of, the dissuasive cigarettes}

232 In general, participants considered the explicit on-cigarette warnings to reduce the appeal of smoking and to be off-putting. Specifically, both the 'TOXIC' and 'smoking kills' cigarettes

234 were deemed to be embarrassing, particularly among female ever-smokers. Some female eversmokers also considered the 'TOXIC' cigarette to be scary, and that the presence of the word 236 toxic would elicit a negative reaction, with one participant mentioning that it would give you a 237 'bad feeling'. While some participants placed slightly greater emphasis on the skull and cross 238 bones image than the word 'TOXIC', in general the image and text appeared to be viewed 239 holistically. While the 'TOXIC' cigarette was viewed negatively by most participants, there 240 was mention in one female ever-smoker group that the cigarette was cool and that it may 241 become a trend and encourage people to want to try them. 
243

244

245

Yeah they are well more embarrassing, can you imagine Justin Bieber [popular music artist] smoking a fag [colloquial term for cigarette] and it says smoking kills in red ink on it (Female ever-smoker)

If you're seeing something with toxic on it, you're not going to want to take it (Male ever-smoker)

They're scary, like it gives you a bad feeling looking at it, it says toxic on it (Female ever-smoker)

Honestly, if they [toxic cigarette] came out, you'd want to buy them to see what they were like (Female ever-smoker).

Initial responses towards both green cigarettes were generally negative for most participants, however, there was further discussion in some groups that colored designs may have an element of appeal to some consumers. Several female ever-smokers thought that the green cigarettes, in particular the lighter green, were embarrassing, ugly and unattractive, compared to the standard cigarette e.g. "They're just ugly, yeah they are a lot uglier than the white ones" (Female ever-smoker). It was also suggested by several male participants that both green cigarettes were horrible, bland, or dull, and that the standard cigarette (white paper and imitation cork filter) was more appealing. Some male never-smokers suggested that the green color, 'TOXIC' symbol and 'smoking kills' could be used together. These perceptions, however, were not unanimous as some participants, particularly some female ever and never- 
266

267

268

269

270

271

272

273

274

275

276

277

278

279

280

281

282

283

284

285

286

287

288

smokers, thought that the use of an unusual or different color, and the lack of health warnings, may create some appeal, while one male ever-smoker group suggested the lighter green cigarette was 'slightly' appealing.

They would be less attractive as well [the green cigarettes], like normal fags [white with imitation cork filter] kind of appeal to like the Hollywood image (Male ever-smoker)

Yeah, they [green cigarettes] just look almost fancy, like if I saw someone with that I'd think, 'oh what is that' (Female never-smoker)

The lighter green is a wee bit more like appealing than the heavy dark green (Male eversmoker)

But the green ones don't say anything, so like you just think it was a fancy green cigarette (Female ever-smoker)

\section{Harm perceptions of dissuasive cigarettes}

The cigarette carrying the 'TOXIC' warning and skull and crossbones image was described as a constant reminder of the harms of smoking, with both males and females suggesting that the use of the skull and cross bones image reminded them of death and other dangerous substances, (e.g. bleach). This perception of harm was also reflected in the show card activity, with the 'TOXIC' cigarette rated as being most harmful in most of the groups. Several participants, mostly ever-smokers, mentioned that the 'smoking kills' message would not be as effective as 
289 the 'TOXIC' message, with the rationale being that people are used to seeing it, possibly on 290 the outer packaging. Some participants, mostly males, also suggested that the 'smoking kills'

291 warning was not always clear, and may not always be seen when the cigarette is being smoked.

The yellow one I think really sticks out, like toxic, that wee [a slang term for small] sign

294 always reminded me death, like you get told not to touch anything like bleach and they've

295 got that sign on it (Female never-smoker)

296

297

You'd be like a walking warning sign ['TOXIC' cigarette] (Female ever-smoker)

298

299

I feel like the smoking kills one is pretty pointless because everyone is so used to hearing 300 that... but the toxic one I feel like that would be better (Female ever-smoker)

I feel like the warning is good but you can't always really see it [smoking kills warning] very well (Male never-smoker)

When ranking the cigarettes based on harm, three of the seven groups (one female ever-smoker and two male never-smoker groups) considered all cigarettes equally as harmful, including the

307 standard cigarette. In the rest of the groups the standard cigarette was ranked the least harmful 308 and the toxic cigarette the most harmful, apart from in the female never-smoker group where 309 both green cigarettes were considered the least harmful. 


\section{Perceived impact of dissuasive cigarettes on smoking attitudes and behavior}

312 Participants generally agreed that the dissuasive cigarettes would make them feel differently

313 about smoking and would be off-putting, in particular, the 'TOXIC' cigarette and, for some 314 males, the green cigarettes.

I feel like the toxic one makes you feel worse about it [smoking] (Male never-smoker)

I think the green ones are the worst out of the bunch, because with the kind of light colors you think [cigarettes with white paper], aw it's kind of normal, then you see something that's like a dark green stick and your like, ew, never mind (Male never-smoker)

322 Concerning smoking attitudes and behavior among other people, most participants believed

323 that the explicit on-cigarette warnings would likely dissuade non-smokers and newer smokers.

324 Specifically, some female ever-smokers suggested that individuals might become cautious and self-conscious about the impact of the cigarettes on their appearance. They also mentioned that there may be an immediate effect in deterring smokers, however, this may diminish over time as they may become desensitized to the messages and designs. There was a consensus, that the

328 cigarettes would have the least impact on established smokers, with some suggesting that such

329 individuals are used to seeing the warnings on the pack already, and any additional affect the 330 cigarettes may have, would fade. 
334 I reckon a lot of it is to do with appearance nowadays and that's not going to be good for 335 your appearance (Female ever-smoker).

Unless you've been smoking for a long time then aye [slang for yes] it would put you off (Male ever-smoker)

I don't know, but I feel like for the first year they would make an impact, but once you're walking about and every single person you see is doing it [smoking dissuasive cigarettes], it would become less embarrassing. Because everyone is in the same boat (Female eversmoker)

\section{DISCUSSION}

346 Adolescents in Scotland had negative reactions towards the four dissuasive cigarette designs

347 and considered them to be embarrassing and off-putting, in particular those with explicit health

348 warnings. They suggested that dissuasive cigarettes would likely be a deterrent for susceptible

349 never-smokers and those who have just begun smoking, but that effectiveness may be limited 350 in established or long-term smokers.

We found that adolescents reported seeing cigarettes on a regular basis, and some

352 reported daily or almost daily exposure. They also suggested that they saw the cigarette more 353 than the outer packaging, which means they are not necessarily exposed to the pictorial 354 warnings and other health messages on standardized packs. Some participants were aware of 355 different types of cigarettes and new design features, such as capsule cigarettes. This is 
356 consistent with past research which suggests young people notice, and pay attention to, 357 cigarette design (Abad-Vivero et al., 2016; Moodie, MacKintosh, Thrasher, McNeill \& 358 Hitchman, 2018). That the cigarette stick is an increasingly important promotional tool for 359 tobacco companies, and as our findings show that adolescents in Scotland are regularly exposed 360 to cigarettes, supports the idea that the cigarette provides a high-reach opportunity to 361 communicate health messages to young people (Moodie et al., 2019).

While adolescents mostly reacted negatively to all four dissuasive designs, the cigarettes which featured explicit warnings were considered the most effective and off-putting, particularly the 'TOXIC' cigarette. The inclusion of a skull and cross bones image - a universal sign of hazardous substances - elicited associations with harm from other dangerous chemicals

366 (e.g. bleach). This is consistent with packaging research which suggests that pictorial warnings 367 have a greater impact than text-only warnings (Hammond, 2011), and a recent qualitative study 368 which found that a cigarette with an image of a 'skull and cross bones' was considered 369 particularly dissuasive (Gallopel-Morvan et al., 2019). Nevertheless, in this study, some female 370 ever-smokers did still suggest that the potential risk factor associated with the 'TOXIC' 371 warning might encourage trial. Consistent with previous research, we also found that some 372 adolescent female ever-smokers considered the 'smoking kills' cigarette warning to be 373 embarrassing (Moodie et al., 2016). Some participants, however, mentioned this message might not be as effective as the 'TOXIC' cigarette, as established smokers may have become 375 desensitized to the message through repeated exposure over time. While initial reactions to the 376 green cigarettes were generally negative, some participants (mostly females) suggested that the 377 color may be considered appealing and some male ever-smokers deemed the lighter green 378 cigarette slightly more appealing than the darker green cigarette. This is not consistent with 379 previous research where different shades of green cigarettes were considered unappealing 380 (Hoek et al., 2016; Moodie et al., 2018b), suggesting that further research into effectiveness of 
381 dissuasive colors is required. Some male never-smokers thought a combination of different 382 dissuasive features (unappealing colour, toxic symbol and 'smoking kills') should be 383 considered. Future research should therefore build upon previous studies that have combined a 384 variety of dissuasive features (Gallopel-Morvan et al., 2019).

Participants generally agreed that the dissuasive cigarettes would put them off smoking,

386 echoing previous quantitative research with adolescents and adults (Drovandi et al., 2019a, 387 2019b; Hoek et al., 2016; Lund \& Scheffels, 2018; Moodie et al., 2016). Concerning the impact 388 on others, it was consistently suggested that the cigarettes would have the strongest impact on 389 deterring newer smokers and susceptible never-smokers, and the effect would be reduced 390 among established smokers. For any impact to be sustained, and given that participants 391 mentioned desensitisation, one option could be to rotate dissuasive designs, for example in a 392 manner similar to the on-pack warnings in the European Union, which are rotated annually. It 393 would be feasible to have text-only warnings on sticks for the first year, unattractively coloured 394 cigarettes for the next year, combined (pictorial and text) warnings for the third year, and so 395 on, particularly as these designs should be considered complementary (Moodie et al., 2018b). 396 The use of a health message (or dissuasive color) on the cigarette stick is already being 397 considered by the Scottish and Canadian governments (Health Canada, 2018; Scottish 398 Government, 2018). While our study was one of the first to explore adolescents' qualitative 399 responses to dissuasive cigarettes, survey research is needed to examine what extent, if at all, 400 reactions to dissuasive cigarettes are associated with reduced trial intentions among 401 adolescents. Research exploring dissuasive cigarettes in a naturalistic context with existing 402 smokers would also be of value, with similar studies conducted with young female smokers 403 prior to the implementation of standardized tobacco packaging (Moodie \& MacKintosh, 2013). 
404 Concerning limitations, we recruited fewer ever-smokers than never-smokers. This may 405 have been due, in part, to participants feeling uncomfortable disclosing their smoking status, 406 or the low smoking prevalence in Scotland among younger people (Scottish Government, 407 2016). The groups were subject to time constraints to fit in with the school schedule, which 408 somewhat limited our ability to probe participants in more detail, and was the reason we 409 explored only four dissuasive cigarette designs. Future research could explore how the current 410 findings compare to cigarettes with different warnings or colours, or other dissuasive designs 411 (e.g. minutes of life lost). The sample size was small, meaning the results cannot be generalized 412 beyond this study, and one group was excluded due a technical fault with the audio recorder. 413 As groups were conducted with pupils from peer groups in a school environment, it is possible 414 that participants provided socially desirable answers, although teachers were deliberately not 415 present to limit potential concerns about disclosure. The cigarettes used in the study had no 416 branding, filter innovation (e.g. flavor-changing capsules) or filter tip design (e.g. star shaped 417 filters), which may have influenced participants' responses. Finally, the focus groups also 418 initially explored knowledge of, and response to, standardized tobacco packaging policy, where 419 participants were free to handle and open the packs (reference removed for blind review). These 420 existing discussions about the potential negative effects of smoking, health warning salience 421 and potential exposure to 'regular' cigarettes (imitation cork filter and white paper casing), 422 may have influenced how participants responded in the dissuasive cigarettes section.

423 In this study, adolescents reported frequent exposure to cigarettes and some were 424 knowledgeable about their use for promotional purposes. Participants had negative reactions 425 to the dissuasive cigarettes, particularly those with warnings, and felt that they would 426 discourage uptake among non-smokers and cessation in newer smokers. Dissuasive cigarettes 427 provide a high-reach opportunity to communicate health messages about smoking to young 
428 people and should therefore form an important component of tobacco control policy concerning 429 the cigarette.

430

431 Acknowledgement: The authors would like to thank all of the participants and schools that 432 took part in the study.

433

434 Funding: Funding was a PhD studentship from [Institution name removed for blind review]. 435

436 Declaration of interest: The authors have no declaration of interests to declare.

437

438 REFERENCES

439 Abad-Vivero, E. N., Thrasher, J. F., Arillo-Santillán, E., Pérez-Hernández, R., Barrientos-

440 Gutíerrez, I., Kollath-Cattano, C., Mejía, R. \& Sargent, J. D. (2016). Recall, appeal and

441 willingness to try cigarettes with flavour capsules: assessing the impact of a tobacco product

442 innovation among early adolescents. Tobacco Control, 25(e2), 113-119. doi:

$443 \quad 10.1136 /$ tobaccocontrol-2015-052805.

444 Anderson, S. J., Glantz S. A., \& Ling P. M. (2005). Emotions for sale: cigarette advertising 445 and women's psychosocial needs. Tobacco Control, 14(2), 127-135. doi:

$446 \quad \underline{10.1136 / \text { tc. } 2004.009076}$

447 Bauld, L., MacKintosh, A., Eastwood, B., Ford, A., Moore, G., Dockrell, M., Arnott, D., 448 Cheeseman, H., \& McNeill. (2017). Young people's use of e-cigarettes across the United 449 Kingdom: findings from five surveys 2015-2017. International Journal of Environmental 450 Research Public Health, 14(9), 973. doi: 10.3390/ijerph14090973. 
451 Braun, V., \& Clarke, V. (2012). Thematic analysis. In H. Cooper, P. M. Camic, D. L. Long, A. 452 T. Panter, D. Rindskopf, \& K. J. Sher (Eds.), APA handbooks in psychology®. APA handbook 453 of research methods in psychology, Vol. 2. Research designs: Quantitative, qualitative, 454 neuropsychological, and biological (p. 57-71). American Psychological Association.

455 Carpenter, C.M., Wayne, G. F., \& Connolly, G. N. (2005). Designing cigarettes for women: 456 new findings from the tobacco industry documents. Addiction, 100(6), 837-851. doi: $457 \quad \underline{10.1111 / \mathrm{j} .1360-0443.2005 .01072 . \mathrm{x}}$

458 Centre for Tobacco Control Research. (2012). The packaging of tobacco products. Stirling, 459 Scotland: Centre for Tobacco Control Research.

460 Critchlow, N., Stead, M., Moodie, C., Angus, K., Eadie, D., \& MacKintosh, A.M. (2019).

461 Difference between recommended retail price and sales price for tobacco products in 462 independent and convenience (small) retailers before and after the introduction of 463 standardised tobacco packaging in the UK. Tobacco control, 28(4), 449-456. doi: $464 \quad \underline{10.1136 / \text { tobaccocontrol-2018-054409 }}$

465 Department of Health. (2016). Guidance for retailers, manufacturers and distributors of 466 tobacco products, enforcement agencies and the public on changes to tobacco packaging 467 from 20 May 2016. Department of Health.

468 Donaghy, E., Bauld, L., Eadie, D., McKell, J., Pringle, B., \& Amos, A. (2013). A qualitative 469 study of how young Scottish smokers living in disadvantaged communities get their 470 cigarettes. Nicotine Tobacco Research, 15, 2053-2059. doi: 10.1093/ntr/ntt095.

471 Drovandi, A., Teague, P.A., Glass, B,. \& Malau-Aduli, B. (2019a). Do health warnings on 472 cigarette sticks dissuade smokers and non-smokers? A focus group and interview study of 
473 Australian university students. Psychology Research Behavioural Management, 15(12), 361. 474 doi: 10.2147/PRBM.S193754

475 Drovandi. A., Teague, P.A., Glass, B., \& Malau-Aduli, B. (2019b). Australian University 476 Student Perceptions of Health Messages on Cigarette Sticks. Health Communication, 1-9. 477 doi: $0.1080 / 10410236.2019 .1567442$.

478 Drovandi, A., Teague, P.A., Glass, B., \& Malau-Aduli, B. (2019c). Australian community 479 pharmacist experiences with smoking cessation and opinions of health warnings on 480 individual cigarette sticks. International Journal of Pharmacy Practice, 27(2), 121-130. doi: $481 \quad$ 10.1111/ijpp.12470.

482 Doxey, J., Hammond, D. (2011). Deadly in pink: the impact of cigarette packaging among 483 young women. Tobacco Control, 20, 353-60. doi: 10.1136/tc.2010.038315

484 Ford, A., Moodie, C., MacKintosh, A.M. \& Hastings, G. (2013a). How adolescents perceive 485 cigarette packaging and possible benefits of plain packaging. Education and Health, 31(2), $486 \quad 83-88$.

487 Ford, A., Moodie, C., MacKintosh, A. M. \& Hastings, G. (2013b). Adolescent perceptions of 488 cigarette appearance. European Journal of Public Health, 24(3), 464-468. doi: $489 \quad 10.1093 /$ eurpub/ckt161.

490 Gallopel-Morvan, K., Droulers, O., \& Pantin-Sohier, G. (2019). Dissuasive cigarettes: which 491 cues are the most effective at deterring young people from smoking? Public Health, 174, 22492 30. doi: 10.1016/j.puhe.2019.05.034.

493 Hammond, D. (2011). Health warning messages on tobacco products: a review. Tobacco 494 control, 20(5), 327-337. doi: 10.1136/tc.2010.037630 
495 Hassan, L., \& Shiu, E. (2013). No place to hide: two pilot studies assessing the effectiveness

496 of adding a health warning to the cigarette stick. Tobacco Control, 24(e1), 3-5. doi:

$497 \quad 10.1136 /$ tobaccocontrol-2013-051238.

498 Hastings, G., and MacFadyen, L. (2000). Keep smiling no one's going to die. Available:

499 http://www.tobaccopapers.com/keepsmiling/KeepSmilingReport.pdf [Accessed November

$50013,2019]$

501 Health Canada. (2018) New health related labelling for tobacco products. Health Canada.

502 Health and Safety Executive. (2019). Hazard Pictograms. Retrieved from

503 http://www.hse.gov.uk/chemical-classification/labelling-packaging/hazard-symbols-hazard-

504 pictograms.htm.

505 Hoek, J., Gendall, P., Eckert, C., \& Louviere, J. (2016). Dissuasive cigarette sticks: the next

506 step in standardised ('plain') packaging? Tobacco Control, 25(6), 699-705. doi:

$507 \quad 10.1136 /$ tobaccocontrol-2015-052533.

508 Kotnowski K, Hammond D. (2013). The impact of cigarette pack shape, size and opening:

509 evidence from tobacco company documents. Addiction, 108(9), 1658-68. doi:

$510 \quad \underline{10.1111 / \text { add.12183 }}$

511 Lund, I., \& Scheffels, J. (2018). Adolescent perceptions of dissuasive sticks: A web survey

512 among 16-20 year olds in Norway. BMC public health, 18(1), 974. doi: 10.1186/s12889-018-

$513 \quad \underline{5847-1}$.

514 MacFadyen, L., Hastings, G., \& MacKintosh, A. M. (2001). Cross sectional study of young

515 people's awareness of and involvement with tobacco marketing. Bmj, 322(7285), 513-517.

$516 \quad$ doi: $10.1136 / \mathrm{bmj} .322 .7285 .513$ 
517 Mitchell, D., Moodie, C., Critchlow, N., \& Bauld, L. (2019). Adolescents’ perceptions of

518 standardised cigarette packaging design and brand variant name post-implementation: a focus

519 group study in Scotland. BMC public health, 19(1), 1227. doi: 10.1186/s12889-019-7552-0

520 Moodie, C. (2016). Novel ways of using tobacco packaging to communicate health messages:

521 Interviews with packaging and marketing. Addiction Research \& Theory, 24(1), 54-61. doi:

$522 \quad \underline{10.3109 / 16066359.2015 .1064905 .}$

523 Moodie, C. (2018). Warnings on every cigarette: extending health messaging to the

524 consumption experience. CMAJ: Cancer Medical Association, 190(43), 1271-1272. doi:

$525 \quad \underline{10.1503 / \mathrm{cmaj} .180781}$

526 Moodie, C., Angus, K., Mitchell, D., \& Critchlow, N. (2018a). How tobacco companies in

527 the UK prepared for and responded to standardised packaging of cigarettes and rolling

528 tobacco. Tobacco Control, 27(e1), 85-92. doi: 10.1136/tobaccocontrol-2017-054011

529 Moodie, C., Ford, A., Dobbie, F., Thrasher, J. F., McKell, J., \& Purves, R. (2017a). The

530 power of product innovation: Smokers' perceptions of capsule cigarettes. Nicotine \&

531 Tobacco Research, 20(9), 1157-1160. doi: 10.1093/ntr/ntx195.

532 Moodie, C., Ford, A., MacKintosh, A. M., \& Purves R (2014). Are all cigarettes just the 533 same? Female's perceptions of slim, coloured, aromatised and capsule cigarettes. Health 534 Education Research, 30(1), 1-12. doi: 10.1093/her/cyu063

535 Moodie, C., Gendall, P., Hoek, J., MacKintosh, A. M., Best, C., \& Murray, S. (2017b). The 536 response of young adult smokers and non-smokers in the United Kingdom to dissuasive 537 cigarettes: An online survey. Nicotine \& Tobacco Research, 21(2), 227-233. doi: $538 \quad \underline{10.1093 / \mathrm{ntr} / \mathrm{ntx} 261}$ 
539 Moodie, C., Hiscock, R., Thrasher, J., \& Reid, G. (2018b). Perceptions of cigarette pack

540 inserts promoting cessation and dissuasive cigarettes among young adult smokers in the UK:

541 a cross-sectional online survey. BMJ open, 8(9), 019662. doi: 10.1136/bmjopen-2017-019662

542 Moodie, C., Hoek, J., Scheffels, J., Gallopel-Morvan, K., \& Lindorff, K. (2019a). Plain

543 packaging: legislative differences in Australia, France, the UK, New Zealand and Norway,

544 and options for strengthening regulations. Tobacco Control, 28(5), 485-492. doi:

$545 \quad 10.1136 /$ tobaccocontrol-2018-054483.

546 Moodie, C., \& MacKintosh, A. M. (2013). Young adult women smokers' response to using

547 plain cigarette packaging: a naturalistic approach. BMJ open, 3(3), e002402. doi:

$548 \quad 10.1136 /$ bmjopen-2012-002402.

549 Moodie, C., MacKintosh, A., Gallopel-Morvan, K., Hastings, G., \& Ford, A. (2016).

550 Adolescents' perceptions of an on-cigarette health warning. Nicotine \& Tobacco Research, 551 19(10), 1232-1237. doi: $\underline{10.1093 / \text { ntr/ntw165 }}$

552 Moodie, C., MacKintosh, A. M., \& Hastings, G. (2015). Adolescents' response to pictorial 553 warnings on the reverse panel of cigarette packs: a repeat cross-sectional study. Tob Control, 554 24(e1), 93-97. doi: 10.1136/tobaccocontrol-2013-050999.

555 Moodie, C., MacKintosh, A.M., Thrasher, J.F., McNeill, A., \& Hitchman, S. (2018d). Use of 556 Cigarettes With Flavor-Changing Capsules Among Smokers in the United Kingdom: An 557 Online Survey (Forthcoming/Available online). doi: 10.1093/ntr/nty 173

558 Moodie. C., Purves, R., McKell, J., \& de Andrade, M. (2015). Novel means of using cigarette 559 packaging and cigarettes to communicate health risk and cessation messages: a qualitative 560 study. International Journal of Mental Health and Addiction, 13(3), 333-344. doi:

$561 \quad 10.1007 / \mathrm{s} 11469-014-9530-1$. 
562 Moodie, C., O’Donnell, R., Fleming, J., Purves, R., McKell, J., \& Dobbie, F. (2019b).

563 Extending health messaging to the consumption experience: a focus group study exploring

564 smokers' perceptions of health warnings on cigarettes. Addiction Research \& Theory, 1-7.

565 doi: $10.1080 / 16066359.2019 .1653861$.

566 Moodie, C., Thrasher, J.F., Cho, Y.J., Barnoya, J., \& Chaloupka, F.J. (2019c). Flavour

567 capsule cigarettes continue to experience strong global growth. Tobacco Control, 28(5), 595-

568 596. doi: 10.1136/tobaccocontrol-2018-054711.

569 NHS Digital. (2018). Statistics on smoking - England 2018. Retrieved from

570 https://digital.nhs.uk/data-and-information/publications/statistical/statistics-on-

571 smoking/statistics-on-smoking-england-2018/part-5-availability-and-affordability-of-tobacco.

572 Scollo, M., Occleston, J., Bayly, M., Lindorff, K., \& Wakefield, M. (2015). Tobacco product

573 developments coinciding with the implementation of plain packaging in Australia. Tobacco

574 Control, 24(e1), 116-122. doi: 10.1136/tobaccocontrol-2013-051509

575 Scottish Government. (2016). Scottish Schools Adolescent Lifestyle and Substance Use 576 Survey (SALSUS) 2015. The Scottish Government.

577 Scottish Government. (2018). Raising Scotland's tobacco free generation: our tobacco

578 control action plan 2018. Retrieved from https://www.gov.scot/publications/raising-

579 scotlands-tobacco-free-generation-tobacco-control-action-plan-2018/pages/3/

580 Tjelta, T., Ritchie, D., \& Amos, A. (2016). "It's Easy to Get Fags": A Qualitative Study of

581 Disadvantaged Young People's Perspectives on Cigarette Availability and Access. Nicotine

582 \& Tobacco Research, 19(12), 1434-1440. doi: 10.1093/ntr/ntw267.

583 UK Government. (2016). Tobacco and Related Products Regulation. UK Government. 
584 Wackowski, O. A., Evans, K. R., Harrell, M. B., Loukas, A., Lewis, M. J., Delnevo, C. D., \&

585 Perry, C. L. (2017). In Their Own Words: Young Adults' Menthol Cigarette Initiation,

586 Perceptions, Experiences and Regulation Perspectives. Nicotine \& Tobacco Research, 20(9),

587 1076-1084.n doi: 10.1093/ntr/ntx048

588 World Health Organization. (2009). Tobacco industry interference with tobacco control.

589 World Health Organisation. (2019). Tobacco. Retrieved from https://www.who.int/news-

590 room/fact-sheets/detail/tobacco. 


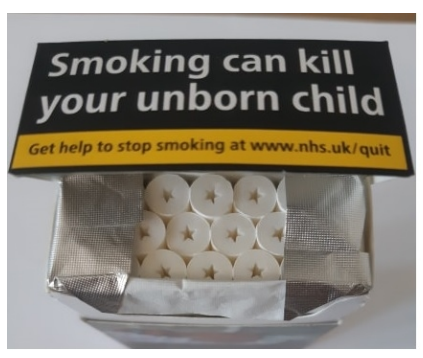

Figure 1: Sterling Dual Star Edition $359 \times 155 \mathrm{~mm}(96 \times 96 \mathrm{DPI})$ 
Table 1: Gender, smoking status and number of participants in each group

\begin{tabular}{cccc}
\hline Group & Gender & Smoking Status & Number of \\
& & & participants \\
\hline $\mathbf{1}$ & Female & Ever-smoker & 5 \\
$\mathbf{2}$ & Female & Ever-smoker & 5 \\
$\mathbf{3}$ & Male & Ever-smoker & 5 \\
$\mathbf{4}$ & Male & Never-smoker & 6 \\
$\mathbf{5}$ & Male & Never-smoker & 5 \\
$\mathbf{6}$ & Male & Never-smoker & 4 \\
$\mathbf{7}$ & Female & Never-smoker & 6 \\
\hline
\end{tabular}


1

2

3

4

5

6

7

8

9

10

11

12

13

14

15

16

17

18

19

20

21

22

23

24

25

26

27

28

29

30

31

32

33

34

35

36

37

38

39

40

41

42

43

44

45

46

47

48

49

50

51

52

53

54

55

56

57

58

59

60

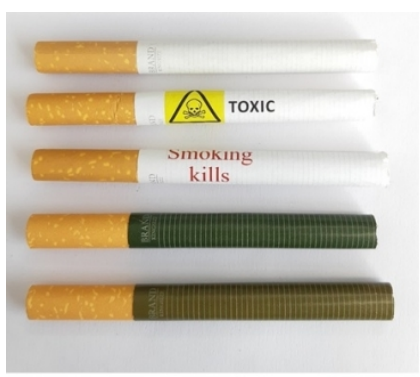

Figure 2: Standard cigarette (top) and the four dissuasive cigarettes (in descending order: Toxic, Smoking Kills, Dark Green, Lighter Green)

$359 \times 155 \mathrm{~mm}(96 \times 96 \mathrm{DPI})$ 